\title{
Evaluation of an Eastern Shale Oil Residue as an Asphalt Additive
}

\author{
Topical Réport \\ December 19, 1995 \\ By: \\ Kenneth P. Thomas \\ P. Michael Harnsberger \\ RECEIVED \\ SEP 291997 \\ O STI
}

Work Performed Under Contract No.: DE-FC21-93MC30126

For

U.S. Department of Energy

Office of Fossil Energy

Federal Energy Technology Center

Morgantown Site

P.O. Box 880

Morgantown, West Virginia 26507-0880

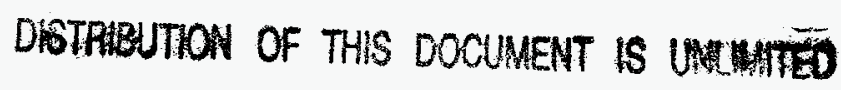

By

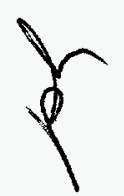

Western Research Institute

365 North Ninth Street

Laramie, Wyoming 82070 


\section{Disclaimer}

This report was prepared as an account of work sponsored by an agency of the United States Government. Neither the United States Government nor any agency thereof, nor any of their employees, makes any warranty, express or implied, or assumes any legal liability or responsibility for the accuracy, completeness, or usefulness of any information, apparatus, product, or process disclosed, or represents that its use would not infringe privately owned rights. Reference herein to any specific commercial product, process, or service by trade name, trademark, manufacturer, or otherwise does not necessarily constitute or imply its endorsement, recommendation, or favoring by the United States Government or any agency thereof. The views and opinions of authors expressed herein do not necessarily state or reflect those of the United States Government or any agency thereof. 


\section{DISCLAIMER}

Portions of this document may be illegible electronic image products. Images are produced from the best available original document. 


\title{
EVALUATION OF AN EASTERN SHALE OIL RESIDUE AS AN ASPHALT ADDITIVE
}

\author{
Kenneth P. Thomas and P. Michael Harnsberger \\ Western Research Institute, 365 N. 9th Street, Laramie, WY 82070-3380
}

\begin{abstract}
An evaluation of eastern shale oil (ESO) residue as an asphalt additive to reduce oxidative age-hardening and moisture susceptibility was conducted. The ESO residue, having a viscosity of $23.9 \mathrm{~Pa} \cdot \mathrm{s}$ at $60^{\circ} \mathrm{C}\left(140^{\circ} \mathrm{F}\right)$, was blended with three different petroleum-derived asphalts, AAD-1, AAK-1, and AAM-1, that are known to be very susceptible to oxidative aging. Rheological and infrared analyses of the unaged and aged asphalts and the blends were then conducted to evaluate oxidative age-hardening. In addition, the petroleum-derived asphalts and the blends were coated onto three different aggregates, Lithonia granite (RA), a low-absorption limestone (RD), and a silicious Gulf Coast gravel (RL), and compacted into briquets. Successive freeze-thaw cycling was then conducted to evaluate the moisture susceptibility of the prepared briquets. The abbreviations used above for the asphalts and the aggregates are part of the Strategic Highway Research Program nomenclature.

The rheological analyses of the unaged petroleum-derived asphalts and their respective blends indicate that the samples satisfy the rutting requirement. However, the aging indexes for the RTFO-aged and RTFO/PAV-aged samples indicate that the blends are stiffer than the petroleum-derived asphalts. This means that when in service the blends will be more prone to pavement embrittlement and fatigue cracking than the petroleum-derived asphalts. Infrared analyses were also conducted on the three petroleum-derived asphalts and the blends before and after RTFO/PAV aging.
\end{abstract}


In general, on RTFO/PAV aging, the amounts of carbonyls and sulfoxides in the samples increase, indicating that the addition of the ESO residue does not mitigate the chemical aging (oxidation) of the petroleum-derived asphalts. This information correlates with the rheological data and the aging indexes that were calculated for the petroleum-derived asphalts and the blends.

The results of the moisture susceptibility test show that all of the briquets prepared using the petroleum-derived asphalts and the blends did not fail after 50 freeze-thaw cycles when constructed using aggregate RD. However, briquets prepared using asphalts $A A D-1$ and $A A K-1$ and the blends prepared from them failed at one freeze-thaw cycle when constructed using aggregates RA and RL. At concentrations of 10 and 15 mass \% ESO residue in petroleum-derived asphalt AAM1 , some improvement in the cycles to failure was noted for briquets prepared using these blends coated onto aggregates RA and RL. The briquets prepared using the blend of 15 mass \% ESO residue and AAM-1 failed at three cycles when coated onto aggregate RA and failed at two cycles when coated onto aggregate RL. To evaluate this apparent trend a blend of 30 mass \% ESO residue and AAM-1 was prepared. When briquets prepared using this blend coated onto aggregates RA and RL were tested, the number of cycles to failure increased to seven and four, respectively. Thus, the trend was substantiated.

\section{INTRODUCTION}

Since the discovery, patenting, and licensing to The New Paraho Corporation of the concept and process for the production of an asphalt modifier that can be produced from western shale oil, 12 test strips have been constructed in five states in the United States (Lukens and Plummer 1988, Harnsberger and Robertson 1994). These states are Wyoming, Colorado, Utah, Texas, and Michigan. The environment of the shale oil-modified asphalt (SOMAT) test strips in these states includes, for example, hot, dry climates (Utah and Texas) and cold, wet climates (Colorado and Michigan). One of the test strips located in Wyoming is west of Rawlins in the westbound driving lane of Interstate 80 . The environment at this location is cold and 
relatively dry but, in addition to the weather, the pavement is also subjected to a very high volume of interstate truck traffic.

One of the more recent test strips was laid in Wyoming in September of 1993. This test strip is 762 meters ( 2500 feet) long and is located in the northbound lane of U.S. Highway 89 north of Jackson, Wyoming. This test strip, which is located in Grand Teton National Park, will continue to be evaluated by personnel from Western Research Institute (WRI) until 1998 both for pavement performance and environmental impact. This test strip represents an evaluation of shale oil-modified asphalt (SOMAT) under extreme climatic conditions. In addition to these 12 test strips, 9.7 kilometers (6 miles) of the westbound driving and passing lanes of Interstate 90 just west of Sundance, Wyoming was reconstructed in the summer of 1994 using this shale oil-derived additive. This represents the first commercial-scale application of SOMAT in the United States.

In the construction of these test strips, 10 to 15 mass $\%$ of the shale oil modifier (SOM) was blended with conventional petroleum-derived asphalt and then the highway was built using conventional construction methods. To date, the results of field evaluations of test strips constructed of SOMAT indicate that the test strips are less susceptible to moisture damage (stripping) than the conventional petroleumderived asphalts that are laid adjacent to the SOMAT test strips. These SOMAT pavements also age more slowly than conventional pavements, which prolongs the time to embrittlement cracking. 
It is known that highly aromatic components, such as those common in eastern shale oil, are as good a dispersant as are the pyridinic components in western shale oil. These are the types of compounds that are needed to improve the compatibility of the components in paving asphalts to reduce aging. A reduction in aging reduces the probability of embrittlement which contributes to fatigue cracking (alligator cracks) that leads to reduced pavement strength and shortened service life. A reduction in cracking also reduces the potential for the invasion of water into and under the pavement, which leads to freeze-thaw deterioration of the pavement. Fatigue cracking constitutes one of the four major forms of asphalt pavement failure, the others being thermal cracking, permanent deformation (rutting and shoving), and moisture damage. In addition, fatigue and permanent deformation are greatly aggravated by moisture damage.

During the last few years, WRI has conducted experiments in cooperation with the University of Kentucky, Center for Applied Energy Research (CAER), to examine residua from eastern shale oil for the same purposes as have been achieved with (Green River formation) western shale oil (Harnsberger and Robertson 1990; Mahboub et al. 1992). While some of the results were encouraging, there was a stability problem with the eastern shale oil residua that were evaluated. Based on the results discussed above, CAER produced and stabilized an eastern shale oil (ESO) residue which was, subsequently, evaluated as an asphalt additive by WRI. 


\section{METHODOLOGY}

On arrival at WRI, the stability of the ESO residue, which was produced from the Cleveland member of the Ohio shale by the KENTORT II process (Carter et al. 1990a; Carter et al. 1994), was evaluated by measuring its viscosity using a Brookfield viscometer, ASTM D 4402 (ASTM 1992). The viscosity of the residue was measured again one month later and the data compared. In addition, the flash point of the residue was determined using ASTM D 92, and the distillate range was determined using a gas chromatographic procedure that relies on the use of an external standard for quantification (Thomas et al. 1987). Since the viscosity of the residue was too low to be suitable for evaluation as an asphalt additive, it was vacuum distilled to produce a material that had a higher viscosity. The vacuum distillation procedure is described by Thomas et al. (1994). The viscosity of the resultant residue was measured and considered to be satisfactory. Consequently, mixtures containing 10 and 15 mass \% of this ESO residue were prepared by blending it with three conventional petroleum-derived asphalts.

The three petroleum-derived asphalts and the six blends were evaluated using the Strategic Highway Research Program (SHRP)-developed and American Association of State Highway and Transportation Officials (AASHTO)-approved specification methods for grading asphalt binders. These methods are used to examine the rheology (viscoelastic properties) of new and artificially aged materials (AASHTO 1994). The results are compared with the AASHTO specification values. All materials were aged artificially to simulate both hot-mix plant aging and pavement 
aging using the rolling thin-film oven (RTFO) and the pressure aging vessel (PAV) methods, T240 and PP1, respectively. The rheological properties of these unaged and aged materials are compared in this report. In addition, the WRI-developed test for evaluating moisture susceptibility of asphalt-aggregate mixtures (Plancher et al. 1980) was conducted on the petroleum-derived asphalts and the blends to demonstrate any advantages that the ESO residue may have to reduce moisture damage in asphaltaggregate mixtures.

\section{RESULTS AND DISCUSSION}

The ESO residue that was evaluated in this study was produced by the CAER using the fluidized bed, KENTORT II process (Carter et al. 1990a; Carter et al. 1994). Stabilization of the shale oil produced by this process was accomplished by distillation of the oil to an initial boiling point of about $204^{\circ} \mathrm{C}\left(400^{\circ} \mathrm{F}\right)$. This stabilized vacuum residue was received at WRI, and an evaluation of the residue as an asphalt additive was initiated. To ensure that the residue was indeed stabilized, the viscosity of a sample of the residue was determined shortly after arrival at WRI and then again one month later. The initial viscosity of the residue was determined to be 1.29 Paos at $60^{\circ} \mathrm{C}\left(140^{\circ} \mathrm{F}\right)$, and its viscosity one month later was determined to be 1.30 Paes at $60^{\circ} \mathrm{C}\left(140^{\circ} \mathrm{F}\right)$. Based on these results, it was concluded that the residue was indeed stable. In addition, the flash point and the initial boiling point of the residue were determined to be $191.5^{\circ} \mathrm{C}\left(377^{\circ} \mathrm{F}\right)$ and $197^{\circ} \mathrm{C}\left(386^{\circ} \mathrm{F}\right)$, respectively. However, the viscosity of the residue was considered to be too low for use as an 
additive in petroleum-derived asphalts. Consequently, the residue was vacuum distilled to produce a material that had an initial boiling point of about $243^{\circ} \mathrm{C}$ $\left(470^{\circ} \mathrm{F}\right)$. The overhead represented about $9 \%$ of the initial charge to the vacuum distillation unit. The viscosity of the vacuum-distilled residue was determined to be 23.9 Pa-s at $60^{\circ} \mathrm{C}\left(140^{\circ} \mathrm{F}\right)$. Thus, if this residue is graded according to ASTM D 3381 , it meets the low-temperature viscosity requirement of an AC-2.5 asphalt. This residue, which is the result of the vacuum distillation procedure, is the material that was used to prepare the ESO residue/petroleum-derived asphalt blends that are the subject of this report.

Late in the study it was discovered that the ESO residue contained about 18 mass $\%$ mineral matter and coke. This was unexpected, because the ash content of the of the composite oil from the KENTORT II process is usually about 2 mass \% (Carter et al. 1990b). This means that the 10 and 15 mass $\%$ blends prepared from the petroleum-derived asphalts and the ESO residue contain about 1.8 and 2.7 mass $\%$ solids, respectively. However, the specifications used for comparison in this study do not contain a maximum limit for solids. A sample of the ESO residue was dissolved in toluene/95\% ethanol $(85 / 15)$ and the mineral matter removed by filtration. The viscosity of the recovered organic material was $33.3 \mathrm{~Pa} \cdot \mathrm{s}$ at $60^{\circ} \mathrm{C}$ $\left(140^{\circ} \mathrm{F}\right)$.

Three petroleum-derived asphalts that exhibit high levels of oxidative aging were selected for this study. They are designated in the SHRP nomenclature as AAD1, AAK-1, and AAM-1. According to ASTM D 3381, these three asphalts are graded 
as an $\mathrm{AR}-4000$, an $\mathrm{AC}-30$, and an $\mathrm{AC}-20$, respectively. The viscosities of these asphalts at $60^{\circ} \mathrm{C}\left(140^{\circ} \mathrm{F}\right)$ are $105.5,325.6$, and 199.2 Paes, respectively. These three asphalts are also different from one another in several other important aspects related to this study. Asphalts AAD-1 and AAK-1 have high propensities for aging. However, while AAK-1 is considered a good asphalt, AAD-1 is only considered marginal for pavement applications in hot climates. Both asphalts contain high concentrations of asphaltenes and sulfur, moderate amounts of nitrogen, and have relatively low molecular weights. However, AAK-1 is more aromatic than AAD-1. Asphalt AAM-1 is rather unusual in that it is a moderately aromatic and moderately waxy asphalt that contains low amounts of nitrogen, sulfur, and asphaltenes, but has a high molecular weight and a moderate propensity for aging. AAM-1 is considered a good asphalt where it has been used in Texas (a hot, aging-prone climate). The ESO residue was mixed with these three common petroleum-derived asphalts at two concentrations, 10 and 15 mass $\%$.

\section{Rheological and Specification Values of the Asphalt-ESO Blends}

The rheological properties were determined for the various aged and unaged samples. The results of aging in the RTFO provide information on the extent of aging that can be expected to occur in a hot-mix plant. An evaluation of the data obtained for samples aged in the RTFO and PAV gives an indication of the extent of aging that will occur in a hot-mix plant and subsequently in the pavement. By plotting the viscoelastic data collected, the maximum and minimum temperature grades of asphalts 
can be determined. To satisfy the high pavement temperature requirement, the performance grades used in Kentucky are PG 58 and 64. For these grades, temperatures of 13,25 , and $31^{\circ} \mathrm{C}\left(55,77\right.$, and $\left.88^{\circ} \mathrm{F}\right)$ represent the range of temperatures used for the mid-range (temperature) rheological evaluation of RTFO/PAV-aged asphalts for fatigue cracking. For the low pavement temperature requirement, these temperatures correspond to $-40,-16$, and $-10^{\circ} \mathrm{C}(-40,3$, and $14^{\circ} \mathrm{F}$ ), respectively and are the lower temperature limits for the minimum pavement design temperature. Temperatures of 58 and $64^{\circ} \mathrm{C}\left(136\right.$ or $\left.147^{\circ} \mathrm{F}\right)$ represent the average seven-day maximum pavement design temperatures. Asphalts that are graded as PG 58 are usually used in eastern Kentucky, while those graded as PG 64 are used in western Kentucky. For the low-temperature requirement, the grades used in Kentucky are -28 and $-34^{\circ} \mathrm{C}\left(-18\right.$ and $\left.-29^{\circ} \mathrm{F}\right)$, with those grades that satisfy the requirements of a -28-grade of asphalt predominating in western Kentucky. The discussion presented above is based on $98 \%$ design reliability. At $50 \%$ design reliability the grade that is used in Kentucky is PG 58-22 (SUPERPAVE Software 1993). For additional information regarding this grading procedure refer to Table I. The $\mathrm{G}^{*} / \mathrm{sin} \delta$ values for the unaged asphalts and blends are shown in Table $\Pi$. This parameter is a measure of the ability of a binder to resist rutting. The value obtained must be greater than the minimum of $1.00 \mathrm{kPa}$ at the test temperature, in this case 58 and $64^{\circ} \mathrm{C}\left(136\right.$ and $\left.147^{\circ} \mathrm{F}\right)$. In all cases, the value of $\mathrm{G}^{*} / \mathrm{sin} \delta$ for the petroleum-derived asphalts and the blends exceeds $1.00 \mathrm{kPa}$. The reason that the values for the three petroleum-derived asphalts are significantly different from one 
another is that they were originally viscosity-graded (according to ASTM D 3381) as AR-4000, AC-30, and AC-20 asphalts. Since the values for $\mathrm{G}^{*} / \sin \delta$ at $58^{\circ} \mathrm{C}\left(136^{\circ} \mathrm{F}\right)$ were significantly greater than $1.00 \mathrm{kPa}$ for petroleum-derived asphalts AAK-1 and AAM-1, these asphalts and the blends made from them were also tested at the next higher temperature, $64^{\circ} \mathrm{C}\left(147^{\circ} \mathrm{F}\right)$.

The results indicate that, at the test temperatures, the petroleum-derived asphalts and their respective blends exceed the minimum requirement; thus, the samples satisfy the rutting requirement. Plots of the $\log$ of $G^{*} / \sin \delta$ versus composition for the petroleum-derived asphalts, the blends, and the ESO residue are shown in Figures 1 and 2. With respect to $\mathrm{AAD}-1$, the blends are on the line, indicating that the addition of the ESO residue to AAD-1 affects G*/sino logarithmically. With respect to AAK-1 and AAM-1, the blends are only slightly below the line. This is not unusual when blending dissimilar residual materials.

The G*/sino values after RTFO aging of the petroleum-derived asphalts and the blends are also contained in Table II. Based on the results obtained for the unaged asphalts, asphalts AAK-1 and AAM-1 and the blends were also evaluated at $64^{\circ} \mathrm{C}$ $\left(147^{\circ} \mathrm{F}\right)$. The minimum requirement for $\mathrm{RTFO}$-aged asphalts is $2.20 \mathrm{kPa}$ at the test temperature. In all cases, the value for $G^{*} / \sin \delta$ for the aged asphalts and the blends exceeds this value. The relative aging index $\left(\mathrm{G}^{*} / \sin \delta_{\mathrm{RTFO} \text {-Aged }}\right.$ versus $\left.\mathrm{G}^{*} / \sin \delta_{\text {Unaged }}\right)$ for all of the asphalts and blends is also shown in Table II. For each set of three, the aging indexes of the blends are higher than for the petroleum-derived asphalts, indicating that they are stiffer. This may imply that when in service the blends will be 
more prone to pavement embrittlement and fatigue cracking than the petroleumderived asphalts.

Also contained in the table are the rheological data for the ESO residue. The aging index for the ESO residue at 58 and $64^{\circ} \mathrm{C}\left(136\right.$ and $\left.147^{\circ} \mathrm{F}\right)$ is extremely high, indicating that this material may be very susceptible to oxidative aging. In addition, this value is probably elevated because of the loss of light ends during the conduct of the RTFO test. It was determined from the RTFO mass loss data that the ESO residue lost about 14 mass $\%$. The test conditions are $163^{\circ} \mathrm{C}\left(325^{\circ} \mathrm{F}\right)$ for 75 minutes with an air flow rate of $4 \mathrm{~L} / \mathrm{min}$ and represent the aging that an asphalt binder experiences during processing in a hot-mix plant. Thus, during testing it is possible that not only did the ESO residue lose light ends, but it was also oxidized -- both circumstances resulting in an increase in the viscosity of this material and, of course, the blends.

The G*sin $\delta$ values after RTFO/PAV aging of the petroleum-derived asphalts and the blends are contained in Table III. This value is a measure of a binder's ability to resist fatigue cracking. The value obtained must be less than the maximum of 5000 $\mathrm{kPa}$ at the test temperature, in this case 13,25 , and $31^{\circ} \mathrm{C}\left(55,77\right.$, and $\left.88^{\circ} \mathrm{F}\right)$. AAD-1 and $A A M-1$ and the blends prepared from them satisfy this parameter at $25^{\circ} \mathrm{C}\left(77^{\circ} \mathrm{F}\right)$, while AAK-1 satisfies this parameter at $31^{\circ} \mathrm{C}\left(88^{\circ} \mathrm{F}\right)$. In addition, the table contains the $\mathrm{G}^{*} / \sin \delta$ values of the RTFO/PAV-aged asphalts and blends at 58 and $64^{\circ} \mathrm{C}(136$ and $\left.147^{\circ} \mathrm{F}\right)$ and the relative aging indexes $\left(\mathrm{G} * / \sin \delta_{\mathrm{RTFO} / \text { PAV-Aged }}\right.$ versus $\left.\mathrm{G} / \sin \delta_{\text {Unaged }}\right)$ for the RTFO/PAV-aged materials. Again, for each set of three, the aging indexes for 
the blends are higher than those for the petroleum-derived asphalts, indicating that they are stiffer. This means that when in service the blends will be more prone to pavement embrittlement and fatigue cracking than the petroleum-derived asphalts. The test conditions in the PAV are $100^{\circ} \mathrm{C}\left(212^{\circ} \mathrm{F}\right)$ and $2.1 \mathrm{MPa}$ air pressure for 20 hours and represent the aging that an asphalt binder experiences while in service as the result of time, temperature, and traffic. The conditions of the test simulate a pavement service life of about 10 years. As observed above on RTFO aging, the ESO residue on RTFO/PAV aging also has an extremely high aging index. The possible reasons for this were discussed above.

To evaluate the impact of the different aging methods on the asphalts and the blends, the relative aging index for PAV aging of the RTFO-aged materials was calculated (G*/sin $\delta_{\text {RTFOPAV-Aged }}$ versus $\left.G * / \sin \delta_{\text {RTFO-aged }}\right)$, and the results are shown in Table IV. In addition, the percentage increase of the aging index as a result of RTFO aging of the unaged binders and PAV aging of the RTFO-aged binders for each asphalt and blend are shown.

The PAV aging index shown in Table IV represents the aging that a pavement would undergo as a result of only the influence of time, temperature, and traffic. In all cases, the relative aging indexes for the blends are greater than those of the petroleum-derived asphalts, again indicating that the blends are stiffer than the asphalts. The aging index for the ESO residue at two temperatures is also shown in the table. Interestingly, the index is fairly low, in this case indicating that the majority of the aging of the ESO residue is the result of the RTFO method. Also included in 
the table are the results of calculating the impact of the different methods of aging on the asphalts and the blends. In general, the percentage increase, after RTFO and after PAV aging of the samples, shows that the blends are more susceptible to aging than the petroleum-derived asphalts.

\section{Oxidative Aging}

Infrared analyses were conducted on the three petroleum-derived asphalts and the blends before and after RTFO/PAV aging to determine changes in the concentrations of the oxygen-containing functional groups (i.e., carbonyls and sulfoxides) present in the samples. The objective of this phase of the study was to determine the ability of the ESO residue to reduce the propensity of these conventional petroleum-derived asphalts to undergo chemical aging (oxidation) as a result of RTFO/PAV aging. The infrared spectroscopic data for the unaged and aged samples are shown in Table V. As shown for the unaged samples, the addition of the ESO residue to the petroleum-derived asphalts usually results in an increase in the amounts of carbonyl and sulfoxide compound types. This is not unusual considering that the shale oil, which was produced by a thermal process, contains appreciable amounts of carbonyl and sulfoxide compound types as is shown in the table. In general, on RTFO/PAV aging, the amounts of carbonyls and sulfoxides in the samples

increases. Also included in the table is the absolute amount of the increase of the carbonyl and sulfoxide concentrations on aging. In general, it appears that the addition of the ESO residue results in an increase in the amount of carbonyls and 
sulfoxides in the aged binders and does not reduce the propensity of the petroleumderived asphalts to undergo chemical aging. Thus, this information correlates with the rheological data and the aging indexes that were calculated for the samples and presented in Tables III and IV.

Petersen et al. (1983) and Epps et al. (1986) observed that there is a direct correlation between the ketone concentration and the viscosity of a modified and unmodified asphalt. Lau et al. (1992) continued this work and demonstrated that there is a direct and linear correlation between the amount of carbonyl and the complex dynamic viscosity of asphalts aged at increasing temperatures and times. In Figures 3,4 , and 5 are plotted the amounts of carbonyl versus $G^{*} / \sin \delta$ for the unaged and RTFO/PAV-aged petroleum-derived asphalts and their respective blends. From the limited data represented in the figures it is apparent that $\mathrm{G}^{*} / \sin \delta$ for the petroleum-derived asphalts and the blends is also directly related to the amount of carbonyl present in the unaged and aged samples. It also appears that at concentrations of 10 and 15 mass \% ESO residue in the petroleum-derived asphalts the slope of the lines are about the same. This implies that on RTFO/PAV aging the oxidation process affects $G^{*} / \sin \delta$ and the carbonyl content of the samples equivalently. 


\section{Moisture Sensitivity}

Asphalt-aggregate briquets were prepared in duplicate using the petroleumderived asphalts and the blends. Three different aggregates were tested. These included Lithonia granite (RA), a low absorption limestone (RD), and a silicious Gulf Coast gravel (RL). The abbreviations are the SHRP nomenclature for these aggregates. The briquets were subjected to repeated freeze-thaw cycling until breakage. The objective of this phase of the study was to evaluate the moisture susceptibility of the prepared asphalt-aggregate samples. The briquets represent combinations that may be used in a pavement constructed of the different binder and aggregate materials. A summary of the data that was collected is shown in Table VI.

The results of the determination of the moisture susceptibility of the petroleum-derived asphalts and the blends when coated onto Lithonia granite (RA) demonstrate that, when the residue is mixed with asphalt AAM-1, some improvement is observed. While briquets prepared using asphalt AAM-1 failed after one to two freeze-thaw cycles, the briquets prepared using the blends failed at two to four cycles. However, the addition of the residue to asphalts AAD-1 and AAK-1 did not improve the moisture susceptibility of these petroleum-derived asphalt blends when coated onto Lithonia granite. Regarding the three petroleum-derived asphalts and the blends when coated onto the low absorption limestone (RD), the briquets did quite well with respect to all asphalts and blends, having not failed after more than 50 cycles. As noted for aggregate RA, when blends of the residue with asphalt AAM-1 are coated onto silicious Gulf Coast gravel (RL), some improvement is also observed. While the 
briquets prepared using the neat asphalt failed after one freeze-thaw cycle, the briquets prepared using the blends broke after two cycles. As in the case of Lithonia granite, the addition of the ESO residue to asphalts AAD-1 and AAK-1 did not result in the improvement of the moisture susceptibility of these petroleum-derived asphalt blends when coated onto silicious Gulf Coast gravel.

Since briquets prepared using blends containing increasing amounts of ESO residue in asphalt AAM-1 appeared to improve the moisture susceptibility of the asphalt when coated onto aggregates RA and RL, a blend of 30 mass \% ESO residue mixed with asphalt AAM-1 was prepared. This material was coated onto the two aggregates, formed into briquets, and the briquets subjected to freeze-thaw cycling. The briquets prepared using this blend failed at seven cycles when coated onto RA and four cycles when coated onto RL. This significant improvement in cycles to failure for briquets prepared using this blend substantiates the trend that was observed initially.

The petroleum-derived asphalt AAM-1 is produced from a West Texas intermediate that has been solvent refined. As mentioned in the beginning of this section, this asphalt is a moderately aromatic and moderately waxy asphalt that contains low amounts of nitrogen, sulfur, and asphaltenes. It is suggested that the addition of the ESO residue, which is composed of relatively high concentrations of heteroatoms and asphaltenes, is providing more of the appropriate types of functional groups necessary for increasing the strength of the interaction between the asphalt and the aggregate. In particular, functional groups such as ketones, sulfoxides, and 
phenols, which are not susceptible to moisture damage (Plancher et al. 1977), are increased in the blends. In addition, the ESO residue is fairly aromatic, thus, the potential for aromatic electron interactions with the aggregate is enhanced. Consequently, the briquets survive more freeze-thaw cycles to failure. With respect to composition, eastern shale oil differs from western shale oil in that the former contains less nitrogen but more sulfur and asphaltenes and is more aromatic (Miknis and Robertson 1987). Shale oils produced from the Ohio shale by the KENTORT II process usually contain about 0.8 mass $\%$ nitrogen and 2 mass \% sulfur and have an $\mathrm{H} / \mathrm{C}$ atomic ratio of 1.4 (Carter et al. 1990b).

\section{CONCLUSIONS}

Three aging-prone petroleum-derived asphalts, AAD-1, AAK-1, and AAM-1, were blended with a stabilized ESO residue. Rheological and infrared analyses were conducted on the petroleum-derived asphalts and the blends to determine their propensity for oxidative age-hardening. In addition, the moisture susceptibility of briquets prepared using the petroleum-derived asphalts or the blends and three different aggregates, Lithonia granite (RA), a low-absorption limestone (RD), and a silicious Gulf Coast gravel (RL), were evaluated by successive freeze-thaw cycling.

The rheological analyses of the unaged petroleum-derived asphalts and their respective blends indicate that the samples satisfy the high pavement temperature stiffness requirement which relates to rutting. However, the aging indexes for the RTFO- and RTFO/PAV-aged samples indicate that the blends age more than the 
petroleum-derived asphalts. This means that when in service the blends will be more prone to pavement embrittlement and fatigue cracking than the petroleum-derived asphalts, as measured by the current AASHTO binder specification methodology. Infrared analyses were also conducted on the three petroleum-derived asphalts and the blends before and after RTFO/PAV aging to determine changes in the concentrations of the oxygen-containing functional groups (i.e., carbonyls and sulfoxides) present in the samples. In general, on RTFO/PAV aging, the amounts of carbonyls and sulfoxides in the samples increase, indicating that the addition of the ESO residue does not mitigate the chemical aging (oxidation) of the petroleumderived asphalts. Thus, this information correlates with the rheological data and the aging indexes that were calculated for the petroleum-derived asphalts and the blends.

The results of the moisture susceptibility testing showed that all of the petroleum-derived asphalts and the blends did not fail after 50 freeze-thaw cycles when coated onto aggregate $\mathrm{RD}$. However, briquets prepared using asphalts $\mathrm{AAD}-1$ and AAK-1 and the blends failed after one freeze-thaw cycle when constructed using aggregates RA and RL. At concentrations of 10 and 15 mass $\%$ ESO residue in asphalt AAM-1, some improvement in the cycles to failure was noted for briquets constructed using aggregates RA and RL. The briquets prepared using a blend of 15 mass \% ESO residue and asphalt AAM-1 failed at three cycles when coated onto aggregate RA and failed at two cycles when coated onto aggregate RL. To evaluate this apparent trend, a blend of 30 mass \% ESO residue and asphalt AAM-1 was prepared. When coated onto aggregates RA and RL, the number of cycles to failure 
of the briquets increased to seven and four, respectively. Thus, the trend noted earlier was substantiated.

\section{ACKNOWLEDGEMENTS}

The authors express appreciation to the United States Department of Energy (DOE), Morgantown Energy Technology Center, for funding this work under Cooperative Agreement Number DE-FC21-93MC30126. However, the opinions, findings, conclusions, or recommendations expressed herein are those of the authors and do not necessarily reflect the views of DOE.

Appreciation is also extended to Dr. Darryl Taulbee and Dr. Scott Carter of the University of Kentucky, Center for Applied Energy Research, for producing and stabilizing the eastern shale oil residue used in this study. The authors also acknowledge Dr. Raymond E. Robertson at Western Research Institute who designed this study and Randall Blake and Janet Wolf who conducted the aging and moisture susceptibility tests on the petroleum-derived asphalts and the blends.

\section{DISCLAIMER}

The mention of specific brand names or models of equipment is for information only and does not imply endorsement by Western Research Institute or the United States Department of Energy. 


\section{REEERENCES}

AASHTO. 1994. AASHTO Provisional Standards, American Association of State Highway and Transportation Officials, Washington, D.C.

ASTM. 1992. Annual Book of ASTM Standards, American Society for Testing and Materials, Philadelphia, PA.

Carter, S.D., T.L. Robl, A.M. Rubel, and D.N. Taulbee. 1990a. Processing of Eastern US Oil Shale in a Multistaged Fluidized Bed System, Fuel, 69(9): 1124-1128.

Carter, S.D., A.M. Rubel, T.L. Robl, and D.N. Taulbee. 1990b. The Development of the KENTORT II Process for Eastern U.S. Oil Shale, Lexington, KY, DOE/LC/11086-2860.

Carter, S.D., D.N. Taulbee, A. Vego, and J.L. Stehn. 1994. Effects of Scale-Up on Oil and Gas Yields in a Solid-Recycle Fluidized Bed Oil Shale Retorting Process, Division of Fuel Chemistry. Amer. Chem. Soc., 39(4): 1253-1257.

Epps, J., J.C. Petersen, T.W. Kennedy, D. Anderson, and R. Haas. 1986. Chemistry, Rheology, and Engineering Properties of Manganese-Treated Asphalts and Asphalt Mixtures, Transportation Research Record 1096, TRB, National Research Council, Washington, D.C., 106-119.

Harnsberger, P.M., and R.E. Robertson. 1990. Evaluation of Western and Eastern Shale Oil Residua as Asphalt Pavement Recycling Agents, Laramie, WY, DOE/MC/11076-2869.

Harnsberger, P.M., and R.E. Robertson. 1994. SOMAT Test Pavement, TR News, No. 171: 32.

Lau, C.K., K.M. Lunsford, C.J. Glover, R.R. Davison, and J.A. Bullin. 1992. Reaction Rates and Hardening Susceptibilities as Determined from Pressure Oxygen Vessel Aging of Asphalts, Transportation Research Record 1342, TRB, National Research Council, Washington, D.C., 50-57.

Lukens, L.A., and M.A. Plummer. 1988. Commercial Feasibility of Producing Shale Oil-Modified Asphalt, Colorado School of Mines Quarterly, 83(4): 108-114.

Mahboub, K., S.D. Carter, R.E. Robertson, P.M. Harnsberger, P.K. Oduroh, A.L. Simpson, and D.N. Taulbee. 1992. Evaluation of the Asphalt Application 
Potential of an Eastern U.S. Shale Oil, Division of Fuel Chemistry. Amer. Chem. Soc., 37(2): 573-580.

Miknis, F.P., and R.E. Robertson. 1987. Characterization of DOE reference oil shales: Mahogany Zone, Parachute Creek Member, Green River Formation Oil Shale, and Clegg Creek Member, New Albany Shale, Laramie, WY, DOE/MC/11076-2448.

Petersen, J.C., H. Plancher, and G. Miyake. 1983. Chemical Reactivity and Flow Properties of Asphalts Modified by Metal Complex-Induced Reaction with Atmospheric Oxygen, Proceedings of the Association of Asphalt Paving Technologists, 52: 32-60.

Plancher, H., S.M. Dorrence, and J.C. Petersen. 1977. Identification of Chemical Types in Asphalts Strongly Absorbed at Asphalt/Aggregate Interface and Their Relative Displacement by Water, Proceedings of the Association of Asphalt Paving Technologists, 46: 151-175.

Plancher, H., G. Miyake, R.C. Venable, and J.C. Petersen. 1980. A Simple Laboratory Test to Indicate the Susceptibility of Asphalt-Aggregate Mixtures to Moisture Damage During Repeated Freeze-Thaw Cycling, Canadian Technical Asphalt Association, XXV: 246-262.

SUPERPAVE Software. 1993. SHRP Asphalt Binder Specification, Heritage Research Group, Indianapolis, IN.

Thomas, K.P., P.M. Harnsberger, and F.D. Guffey. 1994. An Evaluation of Asphalt Ridge (Utah) Tar Sand Bitumen as a Feedstock for the Production of Asphalt and Turbine Fuels, Fuel Science and Technology. International, 12(2): 281302.

Thomas, K.P., J. Oberle, P.M. Harnsberger, D.A. Netzel, and E.B. Smith. 1987. The Effect of Recovery Methods on Bitumen and Heavy Oil Composition, Laramie, WY, WRI Report 90-R-010. 
TABLE I

Performance Graded Asphalt Binder Specification

\begin{tabular}{|l|c|c|c|c|c|c|c|c|c|c|c|}
\hline \multirow{2}{*}{ PERFORMANCE GRADE } & \multicolumn{3}{|c|}{ PG 58- } & \multicolumn{5}{c|}{ PG 64- } \\
\cline { 2 - 10 } & 16 & 22 & 28 & 34 & 40 & 10 & 16 & 22 & 28 & 34 & 40 \\
\hline $\begin{array}{c}\text { Average 7-Day Maximum Pavement } \\
\text { Design Temperature, }{ }^{\circ} \mathrm{C}\end{array}$ & \multicolumn{5}{|c|}{$<58$} & \multicolumn{6}{|c|}{$<4$} \\
\hline $\begin{array}{l}\text { Minimum Pavement Design } \\
\text { Temperature, }{ }^{\circ} \mathrm{C}\end{array}$ & $>-16$ & $>-22$ & $>-28$ & $>-34$ & $>-40$ & $>-10$ & $>-16$ & $>-22$ & $>-28$ & $>-34$ & $>-40$ \\
\hline
\end{tabular}

\begin{tabular}{|l|l|l|}
\hline \multicolumn{2}{|c|}{ ORIGINAL BINDER } \\
\hline $\begin{array}{l}\text { Flash Point Temperature, T48: } \\
\text { Minimum, }{ }^{\circ} \mathrm{C}\end{array}$ & 230 \\
\hline $\begin{array}{l}\text { Viscosity, ASTM D4402: } \\
\text { Maximum, } 3 \mathrm{~Pa} \cdot \mathrm{S}, \\
\text { Test Temperature, }{ }^{\circ} \mathrm{C}\end{array}$ & \multicolumn{3}{|c|}{135} \\
\hline $\begin{array}{l}\text { Dynamic Shear, TP5: } \\
\text { G'/sin } \delta, \text { Minimum, } 1.00 \mathrm{kPa},{ }^{\circ}\end{array}$ & 58 & \\
\hline Test Temperature @ $10 \mathrm{rad} / \mathrm{s},{ }^{\circ} \mathrm{C}$ & & 64 \\
\hline
\end{tabular}

\begin{tabular}{|l|c|c|}
\hline \multicolumn{2}{|c|}{ ROLLING THIN FILM OVEN (T240) OR THIN FILM OVEN RESIDUE (T179) } \\
\hline Mass Loss, Maximum, \% & \multicolumn{2}{|c|}{1.00} \\
\hline $\begin{array}{l}\text { Dynamic Shear, TP5: } \\
\text { G*/sin } \delta, \text { Mhimum, } 2.20 \mathrm{kPa}, \\
\text { Test Temperature @ } 10 \mathrm{rad} / \mathrm{s},{ }^{\circ} \mathrm{C}\end{array}$ & 58 & 64 \\
\hline
\end{tabular}

\begin{tabular}{|c|c|c|c|c|c|c|c|c|c|c|c|}
\hline \multicolumn{12}{|c|}{ PRESSURE AGING VESSEL RESIDUE (PP1) } \\
\hline PAV Aging Temperature, ${ }^{\circ} \mathrm{C}$ & \multicolumn{5}{|c|}{100} & \multicolumn{6}{|c|}{100} \\
\hline 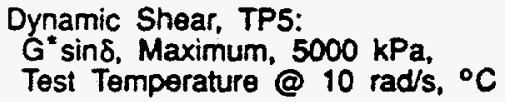 & 25 & 22 & 19 & 16. & 13 & 31 & 28 & 25 & 22 & 19 & 16 \\
\hline Physical Hardening & \multicolumn{11}{|c|}{ Report } \\
\hline $\begin{array}{l}\text { Creep Stiffness, TP1: } \\
\mathrm{S} \text {, Maximum, } 300 \mathrm{MPa}, \\
m \text { - Value, Minimum, } 0.300, \\
\text { Test Temperature @ } 60 \mathrm{~s},{ }^{\circ} \mathrm{C}\end{array}$ & -6 & -12 & -18 & -24 & -30 & 0 & -6 & -12 & -18 & -24 & -30 \\
\hline $\begin{array}{l}\text { Direct Tension, TP3: } \\
\text { Failure Strain, Minimum, } 1.0 \% \text {, } \\
\text { Test Temp. @ } 1.0 \mathrm{~mm} / \mathrm{min},{ }^{\circ} \mathrm{C}\end{array}$ & -6 & -12 & -18 & -24 & -30 & 0 & -6 & -12 & -18 & -24 & -30 \\
\hline
\end{tabular}


TABLE II

Rheological Characteristics of Unaged and RTFO-Aged Samples

\begin{tabular}{|c|c|c|c|c|c|c|}
\hline \multirow[b]{2}{*}{ Sample } & \multicolumn{2}{|c|}{$\begin{array}{c}\mathrm{G}^{*} / \sin \delta \\
\mathrm{kPa}, 58^{\circ} \mathrm{C} \\
10 \mathrm{rad} / \mathrm{s} \\
\end{array}$} & \multicolumn{2}{|c|}{$\begin{array}{c}\mathrm{G}^{*} / \sin \delta \\
\mathrm{kPa}, 64^{\circ} \mathrm{C} \\
10 \mathrm{rad} / \mathrm{s} \\
\end{array}$} & \multicolumn{2}{|c|}{$\begin{array}{c}\text { Relative } \\
\text { Aging Index, } \\
\text { RTFO Aged }\end{array}$} \\
\hline & Unaged & RTFO Aged & Unaged & RTFO Aged & $58^{\circ} \mathrm{C}$ & $64^{\circ} \mathrm{C}$ \\
\hline AAD-1 & 1.65 & 6.60 & -- & -- & 4.0 & - \\
\hline AAD-1/ESO $10 \%$ & 1.27 & 8.69 & -- & - & 6.8 & -- \\
\hline AAD-1/ESO $15 \%$ & 1.22 & 10.51 & -- & -- & 8.6 & -- \\
\hline AAK-1 & 5.16 & 14.84 & 2.78 & 7.23 & 2.9 & 2.6 \\
\hline AAK-1/ESO $10 \%$ & 3.07 & 17.04 & 1.74 & 8.27 & 5.6 & 4.8 \\
\hline AAK-1/ESO $15 \%$ & 2.54 & 23.53 & 1.52 & 10.87 & 9.3 & 7.2 \\
\hline AAM-1 & 3.02 & 7.29 & 1.95 & 3.54 & 2.4 & 1.8 \\
\hline AAM-1/ESO $10 \%$ & 1.75 & 9.40 & 1.14 & 4.74 & 5.4 & 4.2 \\
\hline AAM-1/ESO $15 \%$ & 1.41 & 11.16 & 0.92 & 5.52 & 7.9 & 6.0 \\
\hline $\begin{array}{l}\text { Eastern Shale Oil } \\
\text { (ESO) Residue }\end{array}$ & 0.20 & 3809.0 & 0.10 & 1958.0 & 19,045 & 19,580 \\
\hline \multicolumn{7}{|l|}{ Limit Values, $\mathrm{kPa}$} \\
\hline Minimum & 1.00 & 2.20 & 1.00 & 2.20 & -- & -- \\
\hline Maximum & NA & NA & NA & NA & - & -- \\
\hline
\end{tabular}

NA means not appropriate. 
TABLE III

Rheological Characteristics of RTFO/PAV-Aged Samples

\begin{tabular}{|c|c|c|c|c|c|c|c|}
\hline \multirow[b]{2}{*}{ Sample } & \multicolumn{3}{|c|}{$\begin{array}{c}\mathrm{G}^{*} \sin \delta, \mathrm{kPa} \\
10 \mathrm{rad} / \mathrm{s}\end{array}$} & \multicolumn{2}{|c|}{$\begin{array}{c}\mathrm{G}^{*} / \sin \delta, \mathrm{kPa} \\
10 \mathrm{rad} / \mathrm{s} \\
\end{array}$} & \multicolumn{2}{|c|}{$\begin{array}{c}\text { Relative Aging } \\
\text { Index }\end{array}$} \\
\hline & $13^{\circ} \mathrm{C}$ & $25^{\circ} \mathrm{C}$ & $31^{\circ} \mathrm{C}$ & $58^{\circ} \mathrm{C}$ & $64^{\circ} \mathrm{C}$ & $58^{\circ} \mathrm{C}$ & $64^{\circ} \mathrm{C}$ \\
\hline AAD-1 & 12400 & 2680 & -- & 48.3 & -- & 29.3 & -- \\
\hline AAD-1/ESO $10 \%$ & 15800 & 4110 & -- & 89.3 & -- & 70.3 & -- \\
\hline AAD-1/ESO $15 \%$ & 17800 & 4800 & - & 106.0 & - & 86.9 & -- \\
\hline AAK-1 & 22800 & 5590 & 2080 & -- & 39.5 & -- & 14.2 \\
\hline AAK-1/ESO $10 \%$ & 21800 & 5970 & 3810 & -- & 47.0 & -- & 27.0 \\
\hline AAK-1/ESO $15 \%$ & 20700 & 5560 & 2900 & -- & 74.6 & -- & 49.1 \\
\hline AAM-1 & 14600 & 3800 & 1510 & -- & 21.1 & -- & 10.8 \\
\hline AAM-1/ESO $10 \%$ & 13100 & 4010 & 1780 & -- & 61.8 & -- & 54.2 \\
\hline AAM-1/ESO $15 \%$ & 15200 & 4270 & 1630 & -- & 46.7 & -- & 50.8 \\
\hline $\begin{array}{l}\text { Eastern Shale Oil } \\
\text { (ESO) Residue }\end{array}$ & -- & -- & -- & 8400 & 4510 & 42,000 & 45,100 \\
\hline \multicolumn{8}{|l|}{ Limit Values, $\mathrm{kPa}$} \\
\hline Minimum & NA & NA & NA & - & -- & -- & -- \\
\hline Maximum & 5000 & 5000 & 5000 & -- & -- & -- & -- \\
\hline
\end{tabular}

NA means not appropriate. 
TABLE IV

Impact of Aging Method on the Rheological Characteristics of the Binders

\begin{tabular}{|c|c|c|c|c|c|c|}
\hline \multirow[b]{2}{*}{ Sample } & \multicolumn{2}{|c|}{$\begin{array}{l}\text { Relative Aging } \\
\text { Index. PAV Aged }\end{array}$} & \multicolumn{2}{|c|}{$\begin{array}{l}\text { Increase in Aging } \\
\text { Index. \%. RTFO }\end{array}$} & \multicolumn{2}{|c|}{$\begin{array}{l}\text { Increase in Aging } \\
\text { Index. \%. PAV }\end{array}$} \\
\hline & $58^{\circ} \mathrm{C}$ & $64^{\circ} \mathrm{C}$ & $58^{\circ} \mathrm{C}$ & $64^{\circ} \mathrm{C}$ & $58^{\circ} \mathrm{C}$ & $64^{\circ} \mathrm{C}$ \\
\hline AAD-1 & 7.3 & -- & 300 & -- & 632 & -- \\
\hline AAD-1/ESO 10\% & 10.3 & -- & 584 & -- & 928 & -- \\
\hline AAD-1/ESO 15\% & 10.1 & -- & 761 & -- & 909 & -- \\
\hline AAK-1 & - & 2.0 & -- & 160 & -- & 446 \\
\hline AAK-1/ESO 10\% & -- & 5.7 & -- & 375 & -- & 468 \\
\hline AAK-1/ESO 15\% & -- & 6.9 & -- & 615 & -- & 586 \\
\hline AAM-1 & -- & 6.0 & -- & 82 & -- & 496 \\
\hline AAM-1/ESO $10 \%$ & -- & 13.0 & -- & 316 & -- & 1204 \\
\hline AAM-1/ESO $15 \%$ & -- & 8.5 & -- & 500 & -- & 746 \\
\hline $\begin{array}{l}\text { Eastern Shale Oil } \\
\text { (ESO) Residue }\end{array}$ & 2.2 & 2.3 & $1.9 \times 10^{6}$ & $2.0 \times 10^{6}$ & 121 & 130 \\
\hline
\end{tabular}


TABLE V

Infrared Spectroscopic Analysis of Carbonyls (absorbance units) and Sulfoxides (moles/L) in Unaged and RTFO/PAV-Aged Samples

\begin{tabular}{|c|c|c|c|c|}
\hline \multirow[b]{2}{*}{ Sample } & \multicolumn{2}{|c|}{ Carbonyls / Sulfoxides } & \multicolumn{2}{|c|}{ Increase on Aging } \\
\hline & Unaged & Aged & Carbonyl & Sulfoxide \\
\hline AAD-1 & $0.02 / 0.02$ & $0.09 / 0.38$ & 0.07 & 0.36 \\
\hline AAD-1/ESO $10 \%$ & $0.04 / 0.05$ & $0.14 / 0.46$ & 0.10 & 0.41 \\
\hline AAD-1/ESO 15\% & $0.04 / 0.05$ & $0.15 / 0.53$ & 0.11 & 0.48 \\
\hline AAK-1 & $0.02 / 0.02$ & $0.08 / 0.26$ & 0.06 & 0.24 \\
\hline AAK-1/ESO $10 \%$ & $0.03 / 0.06$ & $0.15 / 0.47$ & 0.12 & 0.41 \\
\hline AAK-1/ESO $15 \%$ & $0.04 / 0.05$ & $0.14 / 0.45$ & 0.10 & 0.40 \\
\hline AAM-1 & $0.04 / 0.02$ & $0.14 / 0.07$ & 0.10 & 0.05 \\
\hline AAM-1/ESO $10 \%$ & $0.02 / 0.11$ & $0.18 / 0.11$ & 0.16 & 0.00 \\
\hline AAM-1/ESO $15 \%$ & $0.04 / 0.10$ & $0.21 / 0.16$ & 0.17 & 0.05 \\
\hline $\begin{array}{l}\text { Eastern Shale Oil } \\
\text { (ESO) Residue }\end{array}$ & $0.22 / 0.27$ & -- & - & -- \\
\hline
\end{tabular}


TABLE VI

Results of Water Susceptibility Tests Conducted on the Briquets

\begin{tabular}{|c|c|c|}
\hline Aggregates & Binders & $\begin{array}{c}\text { Cycles } \\
\text { to Failure }\end{array}$ \\
\hline \multirow[t]{9}{*}{ Lithonia Granite (RA) } & AAD-1 & $1 / 1$ \\
\hline & AAD-1/ESO $10 \%$ & $1 / 1$ \\
\hline & AAD-1/ESO $15 \%$ & $1 / 1$ \\
\hline & AAK-1 & $1 / 1$ \\
\hline & AAK-1/ESO $10 \%$ & $1 / 1$ \\
\hline & AAK-1/ESO $15 \%$ & $1 / 1$ \\
\hline & AAM-1 & $1 / 2$ \\
\hline & AAM-1/ESO $10 \%$ & $3 / 4$ \\
\hline & AAM-1/ESO $15 \%$ & $2 / 3$ \\
\hline \multirow[t]{9}{*}{ Low Absorption Limestone (RD) } & $\mathrm{AAD}-1$ & $>50 />50$ \\
\hline & AAD-1/ESO $10 \%$ & $>50 />50$ \\
\hline & AAD-1/ESO $15 \%$ & $>50 />50$ \\
\hline & AAK-1 & $>50 />50$ \\
\hline & AAK-1/ESO $10 \%$ & $>50 />50$ \\
\hline & AAK-1/ESO $15 \%$ & $>50 />50$ \\
\hline & AAM-1 & $>50 />50$ \\
\hline & AAM-1/ESO $10 \%$ & $>50 />50$ \\
\hline & AAM-1/ESO $15 \%$ & $>50 />50$ \\
\hline \multirow[t]{9}{*}{ Silicious Gulf Coast Gravel (RL) } & AAD-1 & $1 / 1$ \\
\hline & AAD-1/ESO $10 \%$ & $1 / 1$ \\
\hline & AAD-1/ESO $15 \%$ & $1 / 1$ \\
\hline & AAK-1 & $1 / 1$ \\
\hline & AAK-1/ESO $10 \%$ & $1 / 1$ \\
\hline & AAK-1/ESO $15 \%$ & $1 / 1$ \\
\hline & AAM-1 & $1 / 1$ \\
\hline & AAM-1/ESO $10 \%$ & $2 / 2$ \\
\hline & AAM-1/ESO $15 \%$ & $2 / 2$ \\
\hline
\end{tabular}

Duplicate analysis. 


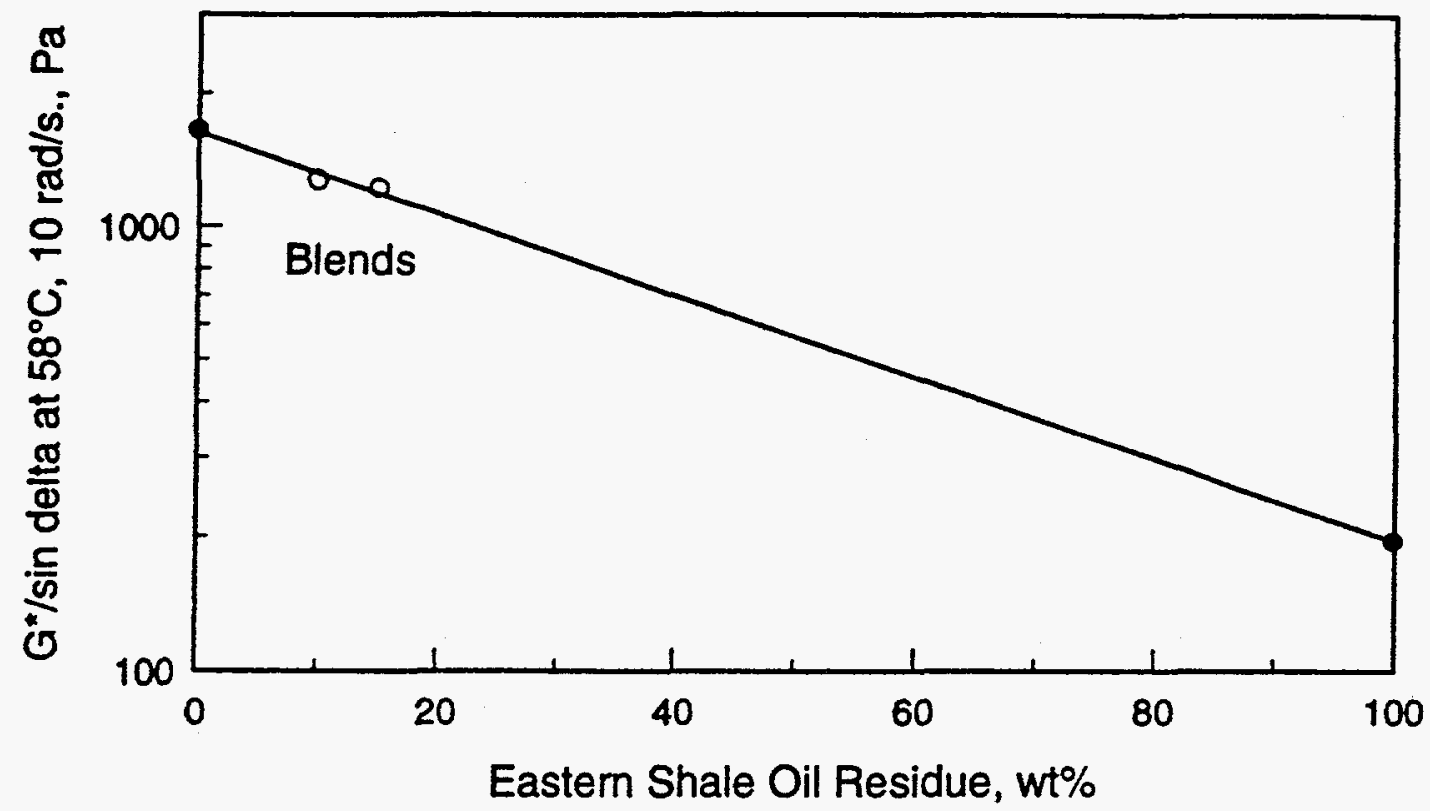

FIG 1. Impact of the Percentage of Eastern Shale Oil Residue on $G^{*} /$ sin delta of Asphalt AAD-1

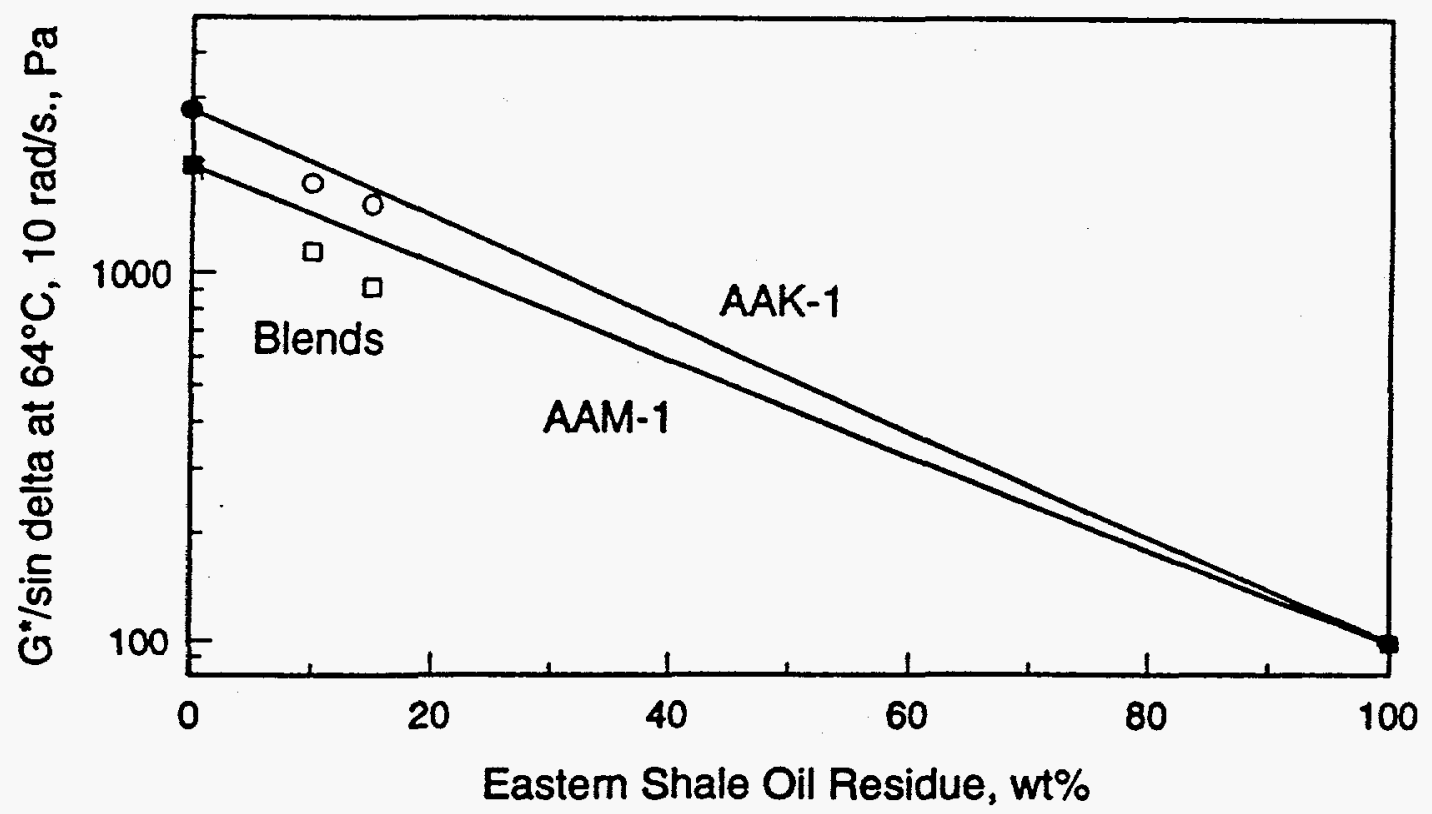

FIG 2. Impact of the Percentage of Eastern Shale Oil Residue on $G^{*} /$ sin delta of Asphalts AAK-1 and AAM-1 


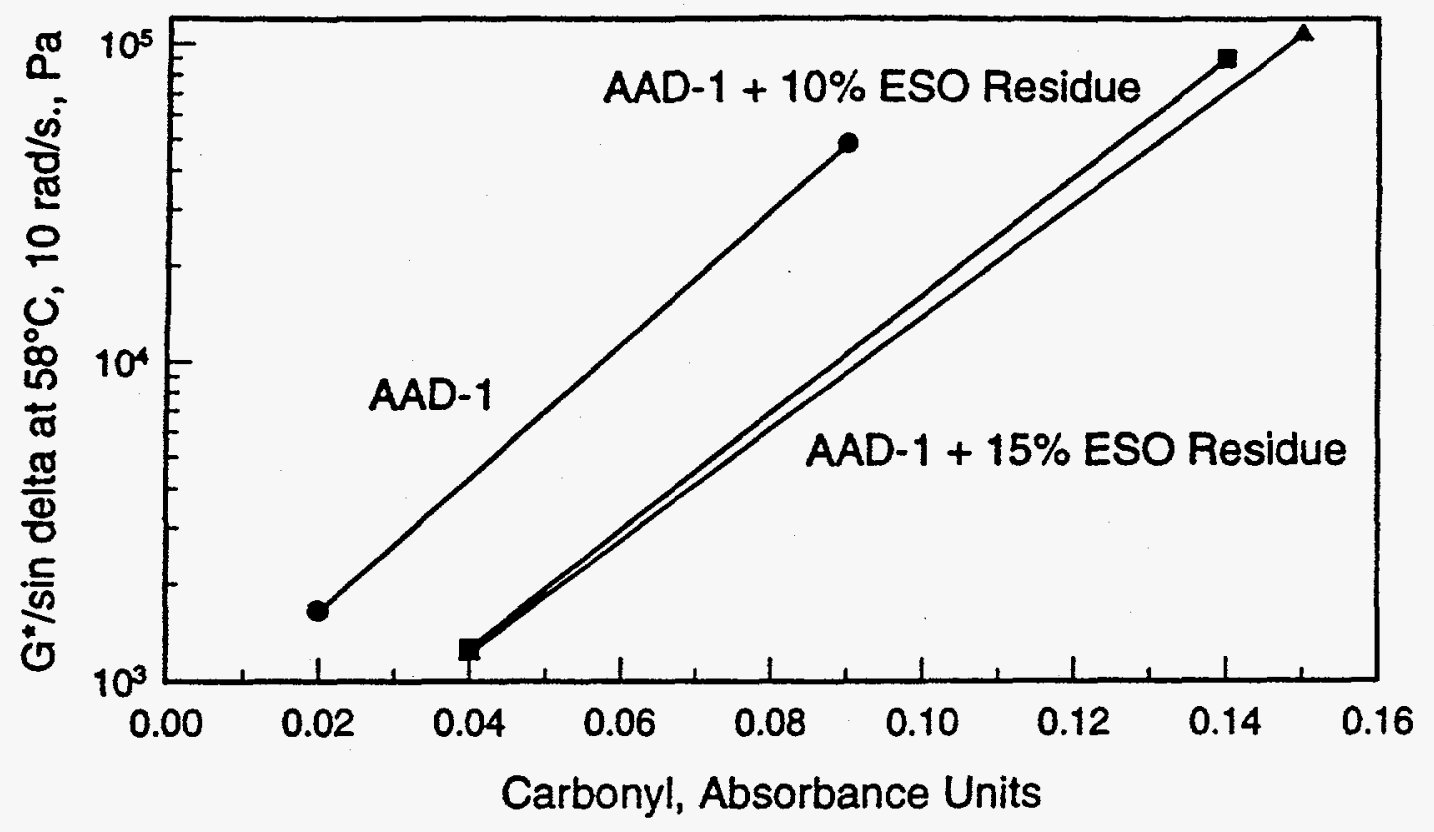

FIG 3. Effect of RTFO/PAV Aging on Asphalt AAD-1 and Blends

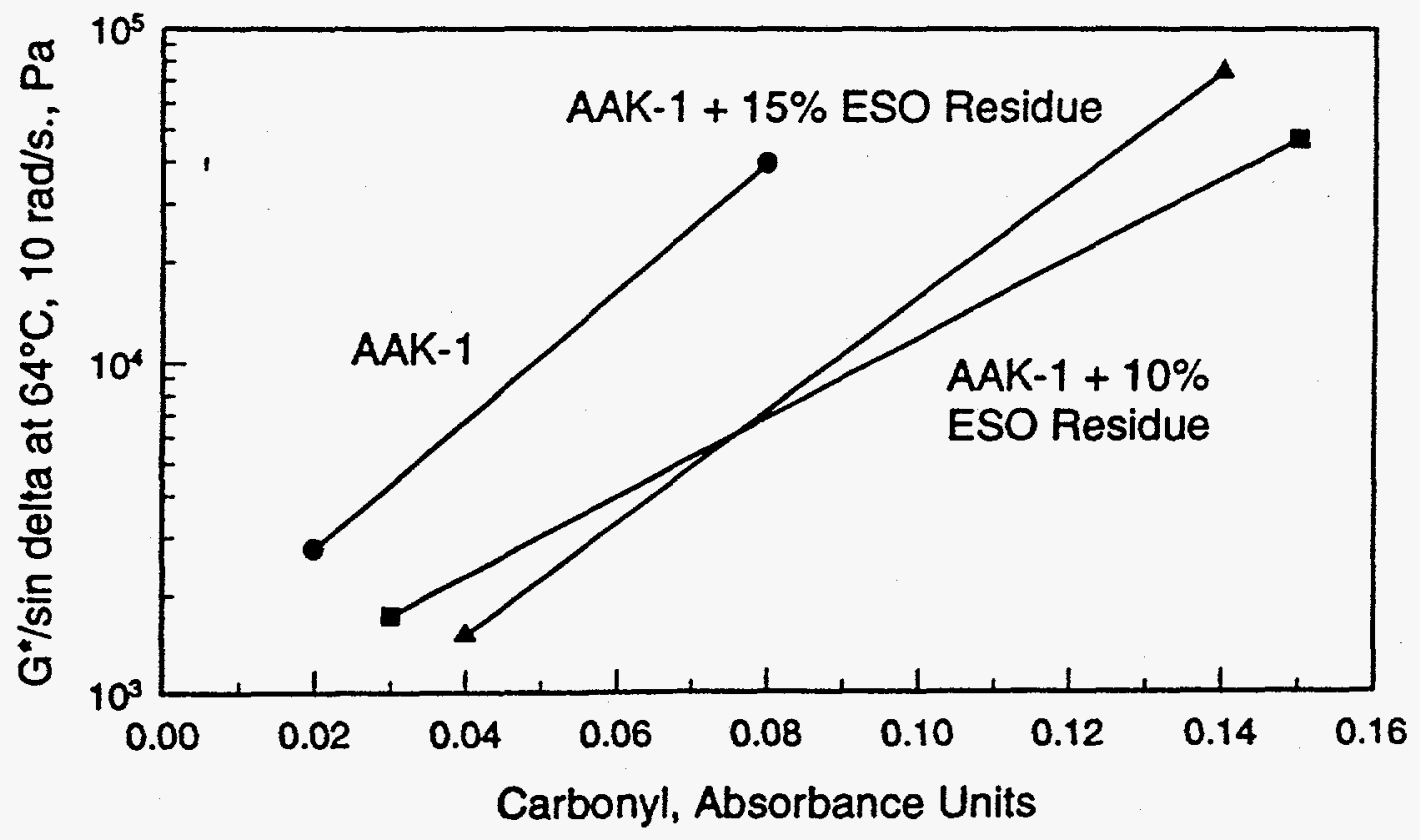

FIG 4. Effect of RTFO/PAV Aging on Asphalt AAK-1 and Blends 


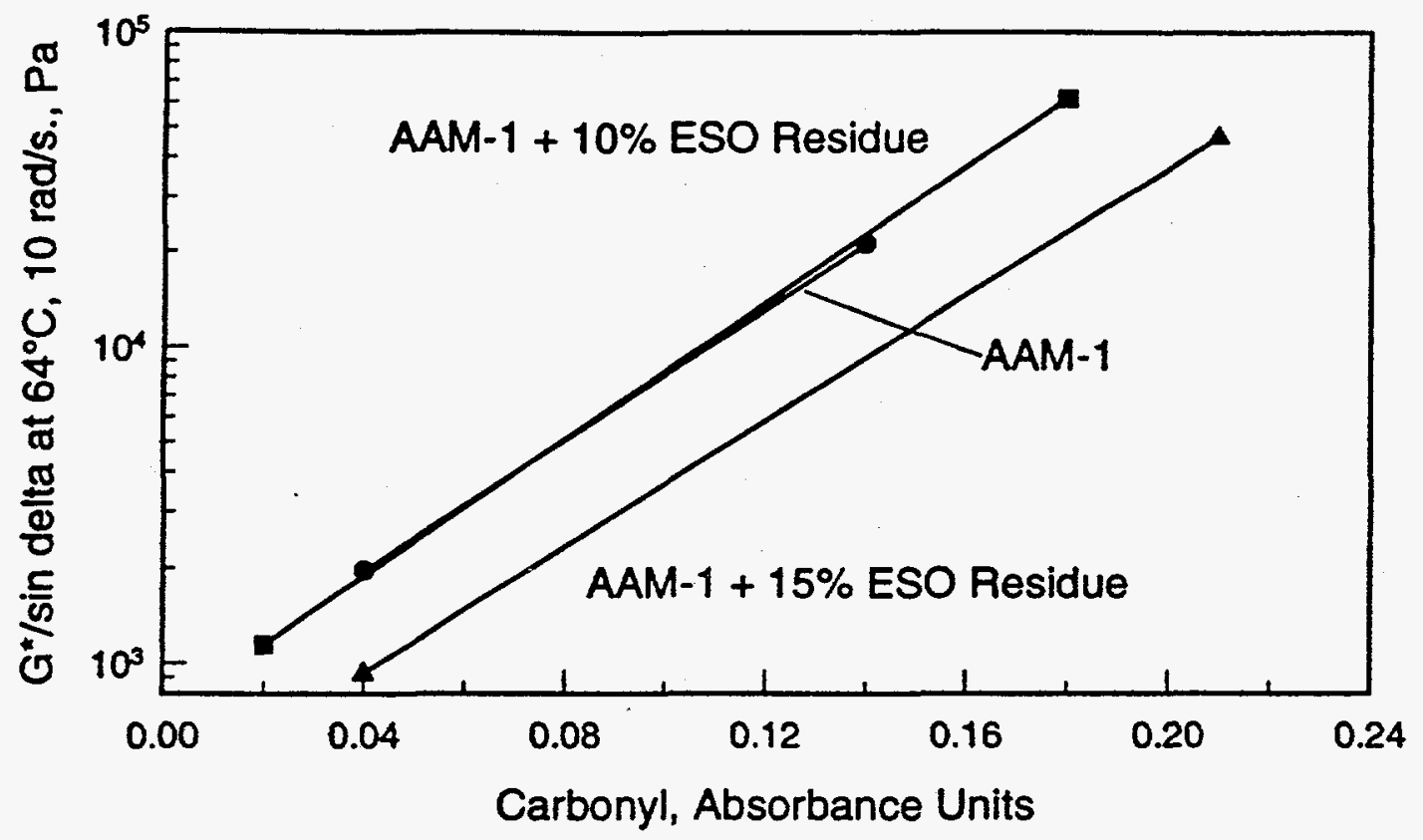

FIG 5. Effect of RTFO/PAV Aging on Asphalt AAM-1 and Blends 